\title{
Magnetic and Cryogenic Design of the MICE Coupling Solenoid Magnet System
}

\author{
L. Wang, F. Y. Xu, H. Wu, X. K. Liu, L. K. Li, X. L. Guo, H. Pan, A. B. Chen, M. A. Green, \\ D. R. Li and S. P. Virostek
}

\begin{abstract}
The Muon Ionization Cooling Experiment (MICE) will demonstrate ionization cooling in a short section of a realistic cooling channel using a muon beam at Rutherford Appleton Laboratory in the UK. The coupling magnet is a superconducting solenoid mounted around four $201 \mathrm{MHz}$ RF cavities, which produces magnetic field up to $2.6 \mathrm{~T}$ on the magnet centerline to keep muons within the iris of RF cavities windows. The coupling coil with inner radius of $750 \mathrm{~mm}$, length of $285 \mathrm{~mm}$ and thickness of $102.5 \mathrm{~mm}$ will be cooled by a pair of $1.5 \mathrm{~W}$ at $4.2 \mathrm{~K}$ small coolers. This paper will introduce the updated engineering design of the coupling magnet made by ICST in China. The detailed analyses on magnetic fields, stresses induced during the processes of winding, cool down and charging, and cold mass support assembly are presented as well.
\end{abstract}

Index Terms - Superconducting Solenoid, Cold mass support, Magnetic field, Stress

\section{INTRODUCTION}

$\mathrm{T}$ HE muon ionization cooling experiment (MICE) will be a demonstration of muon cooling in a configuration of superconducting solenoids and absorbers that may be useful for a neutrino factory [1]. The muon cooling channel contains two spectrometer modules, alternating three absorber focus coil (AFC) modules and two RF coupling coil (RFCC) modules that reaccelerate the muons back to their original longitudinal momentum.

The RFCC module comprises a superconducting coupling solenoid magnet mounted around four conventional conducting 201.25 MHz closed RF cavities bounding by thin beryllium windows [2]. The function of the coupling magnet is to produce enough magnetic fields (up to $2.6 \mathrm{~T}$ on the magnet centerline) to keep the beam within the iris of thin RF cavity windows.

The engineering design of MICE coupling magnet has been carried out by the Institute of Cryogenics and Superconductivity Technology (ICST) in the Harbin Institute of Technology (HIT) in collaboration with the Lawrence

Manuscript received 19 August 2008. This work was supported by Funds of cryogenics and superconductivity technology innovation project under "985-2 Plan" of Harbin Institute of Technology and by the Office of Science, U.S. Department of Energy under Contract No. DE-AC02-05CH11231

L. Wang, F. Y. Xu, H. Wu, X. K. Li, L. K. Li, X. L. Guo, H. Pan, A. B. Chen, are with the Institute of Cryogenics and Superconductive Technology, Harbin Institute of Technology, Harbin 150001, P. R. China (e-mail: wangli_icst@hit.edu.cn)

M. A. Green, D. R. Li , and S. P. Virostek are with the Lawrence Berkeley National Laboratory, Berkeley CA 94720,USA ( e-mail: magreen@1bl.gov).
Berkeley National Laboratory (LBNL) since December 2006. A prototype superconducting solenoid in order to validate the design method and fabrication skills has been fabricated by ICST and is prepared for magnetic performance test in 2008 [4]. This paper presents the updated design of the coupling magnet since the early of 2008 .

\section{Mice Coupling CoIl AsSembly}

The MICE coupling coil is a single $285 \mathrm{~mm}$ long solenoid wound on a 6061-T6-Al mandrel. The inner radius of the coil is $750 \mathrm{~mm}$ and its thickness is $102.5 \mathrm{~mm}$ at room temperature. Table I shows the basic parameters of the coil. The coil is fabricated from standard MRI magnet SC conductor with the critical current about $760 \mathrm{~A}$ at $5 \mathrm{~T}$ and $4.2 \mathrm{~K}$. Using this conductor, the magnet operating margin is expected to be about $0.8 \mathrm{~K}$ when the peak field point is $7.4 \mathrm{~T}$ on the coil with full current of $210 \mathrm{~A}$ and operating temperature of $4.2 \mathrm{~K}$ [3].

TABLE I COUPLING MAGNET SPECIFICATIONS

\begin{tabular}{ccc}
\hline \hline Parameter & Flip & Non-flip \\
\hline Coil Length (mm) & \multicolumn{2}{c}{285} \\
Coil Inner Radius (mm) & \multicolumn{2}{c}{750} \\
Coil Thickness (mm) & \multicolumn{2}{c}{102.5} \\
Number of Layers & \multicolumn{2}{c}{96} \\
No. Turns per Layer & \multicolumn{2}{c}{166} \\
Magnet Self Inductance (H)* & \multicolumn{2}{c}{592.5} \\
Magnet J (A mm $\left.{ }^{-2}\right)^{*}$ & 114.6 & 108.1 \\
Magnet Current (A)* & 210.1 & 198.2 \\
Magnet Stored Energy (MJ)* & 13.1 & 11.6 \\
Peak Induction in Coil (T)* & 7.4 & 7.12 \\
Coil Temperature Margin $(\mathrm{K}) *$ & $\sim 0.79$ & $\sim 1.1$ \\
\hline \hline The Worst case design based on $\mathrm{p}=240 \mathrm{MeV} / \mathrm{c}$ and $\beta=420 \mathrm{~mm}$
\end{tabular}

The coil assembly comprises the coupling coil and the coil mandrel, as shown in Fig.1. The coupling coil is composed of fiberglass cloth, G-10 plates for electrical insulations, epoxy resin, and conductors. The G-10 insulation between the coil and the bobbin, end plates and banding are respectively $1.0 \mathrm{~mm}, 3.0$ $\mathrm{mm}$ and $1.0 \mathrm{~mm}$ thick. The 6061-T6-Al mandrel includes bobbin, end plates, and cover plate, which are respectively 13 $\mathrm{mm}, 19 \mathrm{~mm}$ and $15 \mathrm{~mm}$ thick.

The 3-D view of MICE coupling magnet is shown in Fig. 2, 
which is indirectly cooled by a pair of pulse tube coolers through the liquid helium flowing in extruded tubes attached to the coil assembly using thermo-siphon principle [5].

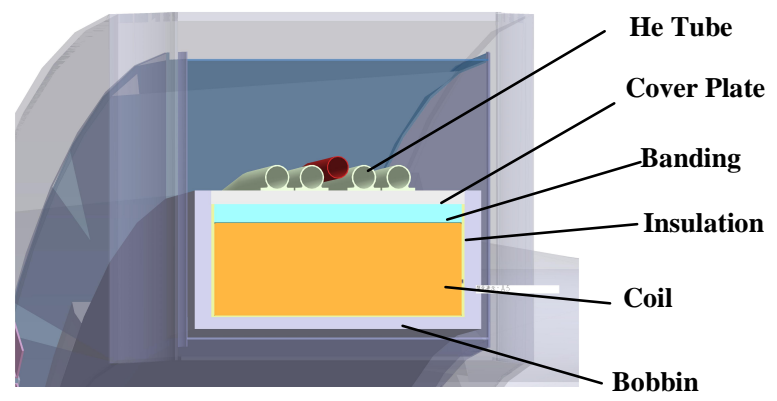

Fig.1. The cross-section of MICE coupling coil assembly

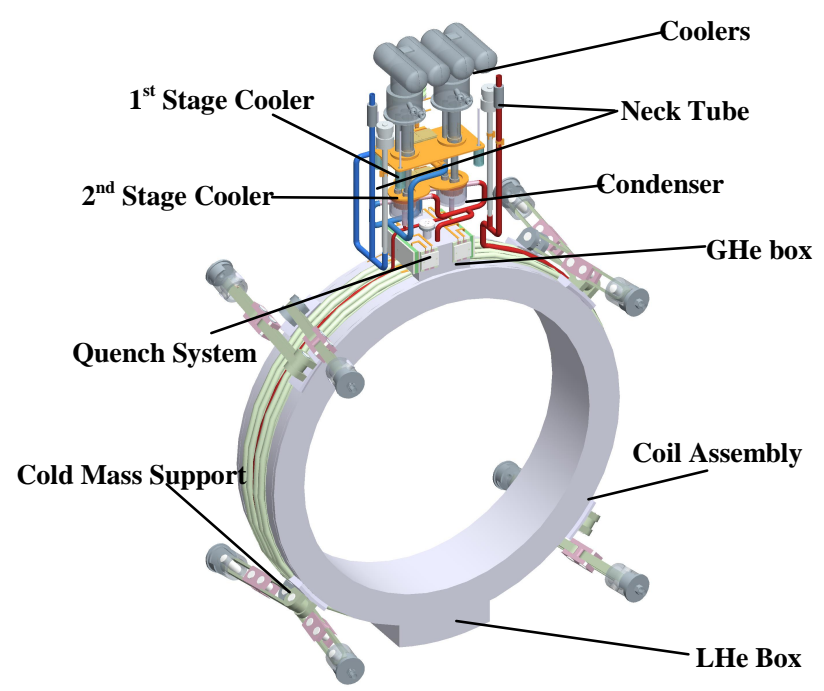

Fig.2. The 3-D view of MICE coupling coil magnet

The magnet will be powered by a $300 \mathrm{~A}, 10 \mathrm{~V}$ power supply through a pair of binary current leads made of HTS leads and copper leads [3]. The magnet is quench protected passively through coil subdivision and inductive coupling with coil mandrel taking benefit of the quench back [6]. The AC losses in the magnet during rapid discharging process will boil away several liters of liquid helium in cooling system. The added volume of liquid helium in liquid helium distribution box and helium gas collection box shown in Fig.2 are used to keep the coil cold during the coil rapid discharge [7].

\section{THE MAGNETIC FIELD}

For the MICE coupling magnet, the performances of the pulse tube cooler rotary valve motor, the HTS leads and the quench cold diodes are affected by the magnetic field and the magnetic flux line direction [8-9]. The magnetic field of the coil at $210 \mathrm{~A}$ is shown in Fig.3. Fig. 3 shows the location of the coil, the cold diodes, the HTS leads and the cooler valve motor

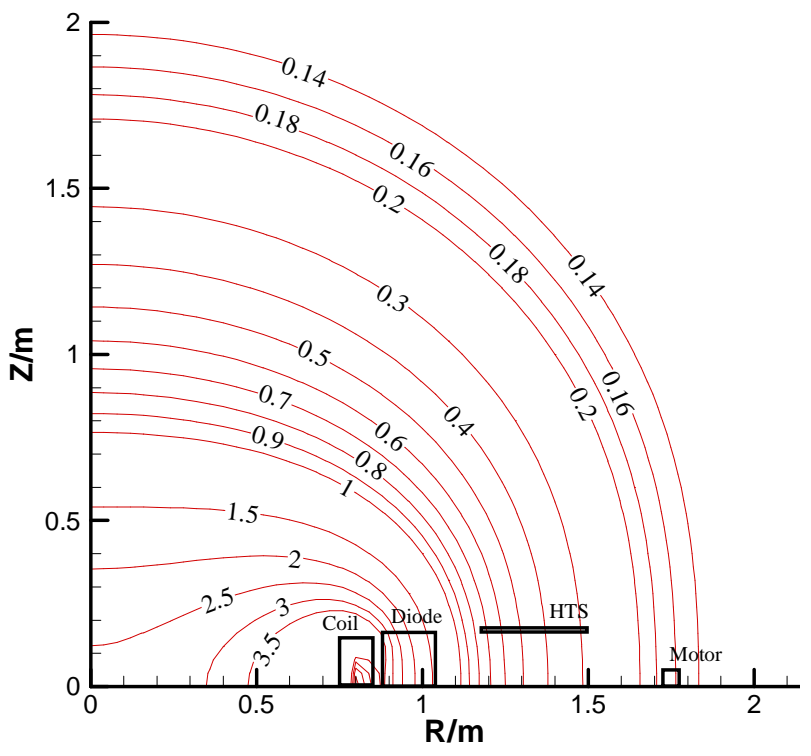

Fig.3 The Magnet field of coupling coil at 210A

\section{A. The Magnetic Effect on the Rotary Valve Motor}

From Fig 3, one can see that the magnetic field around the valve motor is 0.16 to $0.18 \mathrm{~T}$. The magnetic induction at the valve motor must not be greater than $0.05 \mathrm{~T}$. There are two ways to reduce the stray field at the rotary valve motor: 1) The valve can be physically moved to a low field location up to one-meter from the rest of the cold head, which will reduce the cooler performance on both stages by ten to fifteen percent. 2) The valve motor can be shielded with an iron shield. The latter will be adopted because the loss of cooler performance is an issue. At a magnetic induction of $0.18 \mathrm{~T}$, a shield that is the exact dimension of the cooler valve motor aluminum housing will reduce the field in the motor to less than $0.05 \mathrm{~T}$. A rotary valve case fabricated from soft iron instead of aluminum case can fabricated by the cooler vender at little or no extra cost.

\section{B. The Magnetic Effect on the HTS Leads}

The current capacity of HTS-110 leads which are proposed to all MICE magnet is sensitive to the magnet field and its direction at high temperature ends. The HTS-110 lead fabricated from multifilament BSCCO tape has two preferred field directions. The preferred field direction is parallel to the flat face of the lead and the non-preferred is perpendicular to the flat face. The normalized HTS lead current is at $64 \mathrm{~K}$ without external field. The HTS lead should be able to run at 70 $\mathrm{K}$ in the event of a cooler failure or power outage.

The leads of the MICE coupling solenoid will carry a current of $210 \mathrm{~A}$ at the worst case. The magnetic field around the upper ends of HTS leads in the coupling magnet is $0.3 \sim 0.4 \mathrm{~T}$ shown in Fig.3. At a parallel field of $0.4 \mathrm{~T}$, the lead scaling factor is about 0.8 at $64 \mathrm{~K}$ and 0.5 at $70 \mathrm{~K}$ [9]. As a result, a pair of 500A standard HTS-110 leads will be used for MICE coupling solenoid magnet. These leads must be oriented along the preferred field direction. The coupling coil is an axial symmetric solenoid, so the preferred field directions for the HTS leads should be on a radial line from the magnet axis and along a line that is parallel to the magnet axis. 


\section{The Magnetic Effect on the Quench Diodes}

The coupling coil is divided to 8 subdivisions by a pairs of back-to-back R620 diodes and resistor across each subdivision to supply passive quench protection. The total forward voltage across the diodes prevents current form bypassing the coil during a magnet charge or discharge at its design charging and discharging voltage [6]. The forward voltage of quench diodes is very sensitive to the diode temperature, external magnetic field and its direction. The field around the diodes is about 1.5T 3.5T. There are few published reports on effects of high field on the diodes, which suggest the effect is relatively small, but this will be experimentally studied by ICST.

\section{THE COLD MASS SUPPORT SYSTEM}

\section{A. The Support System Parameters}

First, the cold mass support system for the MICE coupling magnet is required to withstand shipping loads at room temperature. Second, after the magnet is cooled down and fully charged, it must withstand the forces put on the magnet during a quench or a fault as well as when the MICE channel is normally operated besides its weight [5]. The cold support system for the coupling coil is designed to carry a longitudinal force up to 500 $\mathrm{kN}$ in either direction, and the radial force of $50 \mathrm{kN}$.

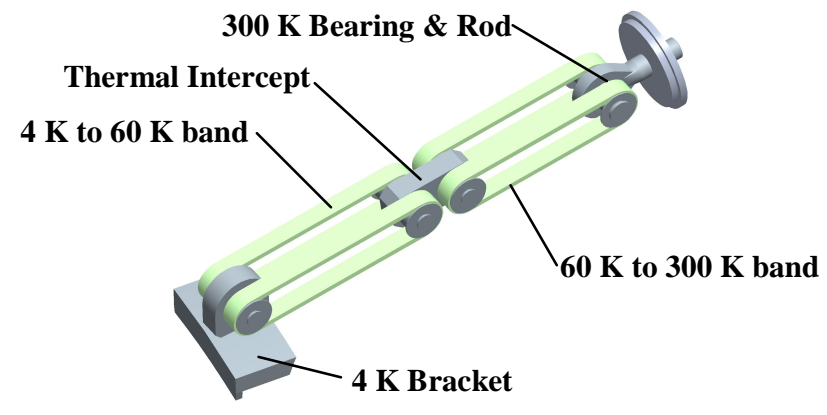

Fig.4. The 3-D schematic of double-band support assembly

The MICE coupling magnet cold mass support is a self-centering tension band support system so that the magnet center does not change during the cooled-down process from $300 \mathrm{~K}$ to $4.2 \mathrm{~K}$. It consists of eight support strap assemblies, four at each end of the magnet. Its warm ends are near the vacuum vessel ends at azimuthal angles of 45, 135, 225, and 315 degrees. The cold ends are at the same angles but they are off by \pm 5 degrees toward the mid-plane to avoid space interference. The support system is configured so that it provides rotational restraint. When the magnet is cooled down from $300 \mathrm{~K}$ to $4 \mathrm{~K}$ and fully charged, the position changes of support cold ends are obtained by FEA method, which are shown in Table II. The position changes of support ends are closely associated with the pre-stress value in bands.

\section{B. The Effect of Magnet Transportation on Pre-stress}

The support system will be sealed by a welded cap at the warm end after the final alignment. Adjustment of the cold mass supports will no longer be possible. Magnet transport will affect the pre-stress level needed in bands at $300 \mathrm{~K}$ and affect the band pre-stress after cool-down and charging.
TABLE II The SUPPort END Positions AT DifFERENT PhASES

\begin{tabular}{cc}
\hline \hline Parameters & \\
\hline Warm End angle (degree) & 45 \\
Warm End R (mm) & 1036.23 \\
Warm End Z (mm) & 582.00 \\
Cold End Angle (degree) & 50 \\
300K Cold End R (mm) & 956.50 \\
300K Cold End Z (mm) & -125.50 \\
4.2K Cold End R (mm) & 952.96 \\
4.2K Cold End Z (mm) & -125.04 \\
4.2K \& Charged Cold End R (mm) & 953.53 \\
4.2K \& Charged Cold End Z (mm) & -125.02 \\
\hline \hline
\end{tabular}

When the coupling magnet is shipped cold, the support system must withstand a dynamic shipping 3-g load at $4.2 \mathrm{~K}$, and when the coupling magnet is shipped warm, the support system should withstand a dynamic shipping load of 2.5-g or $3-\mathrm{g}$ at room temperature depending on the transportation conditions. Table III shows the behavior of the support system as a function of transportation schemes. In the calculations, the band cross-section area is $1280 \mathrm{~mm}^{2}$, the lengths of $60 \sim 300 \mathrm{~K}$ and $4.2 \sim 60 \mathrm{~K}$ bands are $250 \mathrm{~mm}$ and $289 \mathrm{~mm}$ respectively. The support spring constant for each support assembly is $9.61 \times 10^{7}$ $\mathrm{Nm}^{-1}$ and the $300 \mathrm{~K}$ resonant frequency is $40.2 \mathrm{~Hz}$. The table shows that reducing the shipping load is helpful for the support system design.

TABLE III THE COLD MASS SUPPORT SYSTEM PARAMETERS AS FUNCTION OF TRANSPORTATION SCHEMES

\begin{tabular}{cccc}
\hline \hline Band Pre-stress & \multicolumn{3}{c}{ Transportation Schemes } \\
& 3-g warm & 3-g cold & 2.5-g warm \\
\hline 300 K Pre-stress (MPa) & 87.9 & 43.0 & 65.2 \\
4.2 K Cool-down (MPa) & 174.0 & 111.1 & 151.2 \\
4.2K \& Charging (MPa) & 164.9 & 102.0 & 142.2 \\
\hline \hline
\end{tabular}

\section{The Structure and Simulation of Support Assembly}

The support strap assembly has two kinds of structural schemes. The single-band support strap assembly consisting of two oriented fiberglass epoxy bands is shown in Fig.2. The double-band support strap assembly consisting of four oriented fiberglass epoxy bands is shown in Fig.4. The intercept temperature is expected to be about $60 \mathrm{~K}$.

By comparison [5], in terms of stresses and assembly considering limited space, the double-band scheme will be adopted. The width, thickness and inner diameter of the band are respectively $40 \mathrm{~mm}, 8 \mathrm{~mm}$ and $50 \mathrm{~mm}$. In order to reduce the $4 \mathrm{~K}$ region heat leak though the support, the length ratio between $4 \sim 60 \mathrm{~K}$ bands and $60 \sim 300 \mathrm{~K}$ bands is about 1.16:1. The heat leak was calculated using FEA. The heat leaks for one cold mass support from $60 \mathrm{~K}$ to $4.2 \mathrm{~K}$ and $300 \mathrm{~K}$ to $60 \mathrm{~K}$ are respectively $0.0388 \mathrm{~W}$ and $1.19 \mathrm{~W}$. The heat flows down all eight supports are $0.31 \mathrm{~W}$ and $9.52 \mathrm{~W}$ respectively. This is acceptable for two cooler operation of the magnet. 


\section{THE STRESSES IN THE COUPLING COIL}

The stresses in the MICE coupling coil during the processes of winding, cool down and charging should be studied to predict the proper value of pre-tension force for winding the coil, and to check the stress and strain condition in the coil assembly and verify the structural design for the coil mandrel.

The stress and strain within MICE coupling coil is analyzed using FEA method. The winding pre-stresses of 90MPa and $30 \mathrm{MPa}$ are applied in the coil and the banding respectively. The coil, banding, ground insulations, mandrel and cover plate are combined together in the FEA model.

\section{A. After winding the coil onto the mandrel}

As shown in Fig.5, the compressive hoop stress reduces along the radial direction from the inner layer to the outer layer. The hoop stress at the outmost layer of the coil is in tension about $87 \mathrm{MPa}$, which decreases a little after winding the banding. The stress gradient in the coil decreases along the radial direction.

Along the longitudinal direction the compressive hoop stress in the center on the inner layers is higher than that close to the edges, and the inward deflection in the center is more than that close to the edges because the mandrel close to the edges is thicker than that in the center. With winding the conductors layer by layer, the hoop stress along the longitudinal direction tends to be almost the same.

\section{B. During cool down from $300 \mathrm{~K}$ to $4.2 \mathrm{~K}$}

Due to different thermal expansion coefficients, the mean integral thermal expansion coefficient from $300 \mathrm{~K}$ to $4 \mathrm{~K}$ of the coil is about $80 \%$ of that of the mandrel and cover plate. The inner Al bobbin will pull the coil inward, and the outer cover plate will also push the coil inward, which results in increasing of the stress in the coil. The peak compressive stress is about $135 \mathrm{MPa}$ in the inner center of the coil. The tensile stress on the outmost layer is about $40 \mathrm{MPa}$.

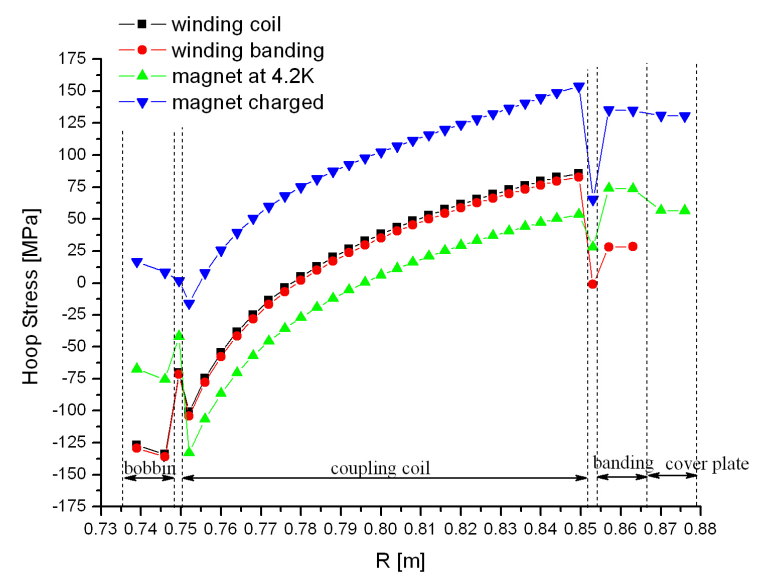

Fig.5 The hoop stress in the centre of coil along the radial direction

\section{After charged to full current}

The compressive hoop stress in the coil was released greatly due to magnetic force. The stress distributed adjacent to the centre of the coil on the inner layers is in compression, and the stress close to the edges changes to be in tension. Most of the stress in the coil changes to be in tension. The peak tensile hoop stress is about $150 \mathrm{MPa}$ on the outmost layer. The compressive hoop stress in the inner central surface is about $20 \mathrm{MPa}$, which means the coil doesn't separate from the bobbin. The mandrel is in tensile condition.

The combined peak von Mises stress appearing at the centre of the outmost layer is about $183 \mathrm{MPa}$, which is higher than the allowable stress of $170 \mathrm{MPa}$. The pre-stress for winding shall be reduced from $90 \mathrm{MPa}$ to $70 \mathrm{MPa}$, and the corresponding wire tensile stress is $87.9 \mathrm{MPa}$ which means that the tensioning force is $132 \mathrm{~N}$.

\section{CONCLUSION}

The effects of the coupling coil magnetic field and its direction on the performance of the rotary valve motor, HTS leads and quench cold diodes are discussed in detail, and the possible solutions are presented. The effects of transportation schemes on support system are analyzed and a double-band self-centering cold mass support system is introduced here. The stresses in the coupling coil during winding, cool down and charging process are analyzed, and the pre-stress for winding is set as low as $70 \mathrm{MPa}$. The analyzed results will be further verified by the performance test of the prototype superconducting solenoid in ICST, China.

\section{REFERENCES}

[1] G. Gregoire, G. Ryckewaert, L. Chevalier, et al, "MICE and International Muon Ionization Cooling Experiment Technical Reference Document," http://hep04.phys.itt.edu/cooldemo.

[2] D., Li, M. A. Green, S. P. Virostek, M. S. Zisman,, "Progress on the RF Coupling Module for the MICE Channel," Proceedings of 2005 Particle Accelerator Conference Knoxville TN, p 3417, 2005

[3] L. Wang, M. A. Green, F. Y. Xu, et al, "The Engineering Design of the $1.5 \mathrm{~m}$ Diameter Solenoid for the MICE RFCC Modules," IEEE Transactions on Applied Superconductivity 18, No. 2, p 937, (2008).

[4] L. Wang, H. Pan, F.Y. Xu, H. Wu, et al, "Design and Construction of Test Coils for MICE Coupling Solenoid Magnet," submitted to IEEE Transactions on Applied Superconductivity 19, (this volume) August 2008.

[5] L. Wang, H. Wu, L. K. Li, et al, "Helium Cooling System and Cold Mass Support System for the MICE Coupling Solenoid," IEEE Transactions on Applied Superconductivity 17, No. 2, p 1251, (2008).

[6] X. L. Guo, F.Y. Xu, L. Wang, M. A. Green, et al "Quench Protection for the MICE Cooling Channel Coupling Magnet," submitted to IEEE Transactions on Applied Superconductivity 19, August 2008.

[7] H. Wu, L. Wang, X. K. Liu, et al, "A Single-band Cold Mass Support System for MICE Superconducting Coupling Magnet," Proceedings of ICCR2008 Shanghai in China, p 3512008.

[8] M. A. Green and H. Witte, "The Use of Small Cooler in a Magnetic Field," Advances in Cryogenic Engineering 53, p 1299, AIP Press, Melville NY (2008)

[9] M. A. Green, S. Q. Yang, et al, "The Effect of Magnetic Field on the Position of HTS Leads and the Cooler in the Services Tower of the MICE Focusing Magnet," IEEE Transactions on Applied Superconductivity 15, No.2, p 1447, 2008. 
This document was prepared as an account of work sponsored by the United States Government. While this document is believed to contain correct information, neither the United States Government nor any agency thereof, nor The Regents of the University of California, nor any of their employees, makes any warranty, express or implied, or assumes any legal responsibility for the accuracy, completeness, or usefulness of any information, apparatus, product, or process disclosed, or represents that its use would not infringe privately owned rights. Reference herein to any specific commercial product, process, or service by its trade name, trademark, manufacturer, or otherwise, does not necessarily constitute or imply its endorsement, recommendation, or favoring by the United States Government or any agency thereof, or The Regents of the University of California. The views and opinions of authors expressed herein do not necessarily state or reflect those of the United States Government or any agency thereof, or The Regents of the University of California. 